\title{
Effective monitoring and management of peatland restoration
}

Rupesh K. Bhomia

Daniel Murdiyarso 

Working Paper 270

\section{Effective monitoring and management of peatland restoration}

Rupesh K. Bhomia

Daniel Murdiyarso 
Working Paper 270

(C) 2021 Center for International Forestry Research

(c) (1) Content in this publication is licensed under a Creative Commons Attribution 4.0 International (CC BY 4.0), http://creativecommons.org/licenses/by/4.0/

DOI: $10.17528 /$ cifor/008142

Bhomia RK and Murdiyarso D. 2021. Effective monitoring and management of peatland restoration. Working Paper 270. Bogor, Indonesia: CIFOR.

CIFOR

JI. CIFOR, Situ Gede

Bogor Barat 16115

Indonesia

$\mathrm{T}+62$ (251) 8622-622

$F+62$ (251) 8622-100

E cifor@cgiar.org

cifor.org

We would like to thank all funding partners who supported this research through their contributions to the CGIAR Fund. For a full list of the 'CGIAR Fund' funding partners please see: http://www.cgiar.org/our-funders/

Any views expressed in this publication are those of the authors. They do not necessarily represent the views of CIFOR, the editors, the authors' institutions, the financial sponsors or the reviewers. 


\section{Contents}

Summary

$\mathbf{v}$

Acknowledgements

vi

Contributors

vii

Foreword

1 Introduction 1

2 Peatland restoration in Indonesia $\quad 2$

3 Advances in peatland restoration monitoring approaches 4

4 Principles, criteria and indicators for peatland restoration 7

4.1 Identification 7

4.2 Consultative process 9

4.3 Biophysical aspects 10

4.4 Economic aspects 10

4.5 Social aspects $\quad 12$

4.6 Governance aspects 12

$\begin{array}{ll}4.7 \text { Verification } & 13\end{array}$

5 Synthesis $\quad 14$

6 Way forward 16

$\begin{array}{ll}\text { References } & 17\end{array}$ 


\section{List of figures, tables and boxes}

\section{Figures}

1 Step-by-step approach to peatland restoration, as undertaken by Indonesia's Peatland Restoration Agency (Wardhana, 2016)

2 Key parameters to be monitored to achieve holistic peatland restoration (FAO 2020)

4 Four-part organization of the webinar series to identify principles, criteria and indicators for peatland restoration

5 A synthesis of the peatland restoration webinar series and main learning points

\section{Tables}

1 Identified criteria and indicators relating to biophysical aspects of peatlands 10

2 Identified criteria and indicators relating to economic aspects of peatlands 11

3 Identified criteria and indicators relating to social aspects of peatlands 12

4 Identified criteria and indicators relating to governance aspects of peatlands 13

\section{Box}

1 A demand-driven approach to identify peatland monitoring principles, criteria and indicators 


\section{Summary}

Peatland restoration needs to be underpinned by monitoring efforts that allow for an adaptive approach to peatland restoration. This monitoring can inform design, strategy, site selection and management approaches, as well as improve restoration efforts through adjustments. Tested protocols that assess the fate of restored ecosystems are useful so that practitioners and institutions can determine the success and failures of peatland restoration objectively. Of particular help are simple indicators that are easy to recognize, measure and monitor over time. Therefore a scientifically robust, reliable and practical set of criteria and indicators (C \& I) could help key stakeholders assess the progress and outcomes of restoration efforts and evaluate advances and whether restoration is heading in the right direction.

With this in mind, between September and December 2020, CIFOR organized a series of online workshops to explore principles, criteria and indicators (P, C \& I) for tropical peatland restoration in Indonesia. Four workshops took place, in which national and international representatives of government, universities, non-government and research organizations discussed the key aspects of peatland restoration and deliberated on practical ways to monitor restoration success. In total, these webinars involved 20 sessions, with 50 speakers and 18 moderators facilitating 11 discussions, attended by 827 participants across the globe. A key message that emerged in these workshops was a need for greater emphasis on the 'five Rs' - rewetting drained peatlands, reducing fire risks, revegetating landscapes, reinforcing local governance structures, and revitalizing local communities' socio-economic conditions.

A number of bio-physical, social, economic and governance criteria and indicators also emerged from these sessions. These now needs to be applied and tested in real field settings before wider adoption and implementation. These indicators include: bio-physical indicators - relating to the ecological, hydrological and fire aspects of peatland - so stakeholders can monitor the restoration and maintenance of peatland hydrologic units' integrity, as well as fire risk reduction; social indicators - relating to social networks, equity, trust and justice - so stakeholders can determine the extent of democratic processes and participation, conflict resolution and volunteerism, which are all important for social solidarity; economic indicators, particularly to monitor existing incentives and new livelihood options in peatland landscapes; and governance indicators, to explore what policies are needed and appropriate at local, provincial and national level for successful implementation. Taking a balanced approach to monitoring that covers all four aspects will mean restoration targets can be adequately quantified, and success can be measured across the board. Adoption of $P, C \& I$ by relevant agencies will help in adaptive management and decision-making processes towards peatland restoration, both within Indonesia and across the globe. 


\section{Acknowledgements}

This Working Paper, and the online workshop series it is based upon, were made possible by the financial support of the United States Agency for International Development (USAID) to the Center for International Forestry Research (CIFOR). CIFOR also acknowledges the immense support from the Indonesian Ministry of Environment and Forestry (MoEF), the Peatland Restoration Agency (BRG) and the International Tropical Peatlands Center (ITPC). CIFOR is thankful to the Food and Agriculture Organization of the United Nations (FAO), UN Environment Programme World Conservation Monitoring Centre (UNEP-WCMC) and Global Peatlands Initiative (GPI) for their valuable contributions. And finally, CIFOR acknowledges all experts representing practitioners, researchers, and government officials who contributed by sharing both information and their practical field experiences. 


\section{Contributors}

The outcomes of this online workshop series are the result of generous contributions made by a large community of researchers, practitioners, academics and government officials, representing a wide range of organizations and sectors. The following table illustrates the diversity of experts whose inputs were crucial in shaping four webinars which led to this working paper.

\begin{tabular}{|c|c|c|c|}
\hline No. & Name & Position & Organization \\
\hline 1 & Alue Dohong & Vice Minister & Ministry of Environment and Forestry (MoEF) \\
\hline 2 & Nazir Foead & Former Head & Peatland Restoration Agency (BRG) \\
\hline 3 & Haruni Krisnawati & Senior Researcher & $\begin{array}{l}\text { Research arm of the Development and Innovation } \\
\text { Agency, MoEF }\end{array}$ \\
\hline 4 & SPM Budisusanti & Director & Peatland Degradation Control, MoEF \\
\hline 5 & Lera Miles & $\begin{array}{l}\text { Principal Technical } \\
\text { Specialist }\end{array}$ & $\begin{array}{l}\text { Planning for Places, UN Environment Programme } \\
\text { World Conservation Monitoring Centre } \\
\text { (UNEP-WCMC) }\end{array}$ \\
\hline 6 & Maria Nuutinen & Forestry Officer & $\begin{array}{l}\text { Food and Agriculture Organisation of the United } \\
\text { Nations (FAO) }\end{array}$ \\
\hline 7 & Daniel Murdiyarso & Principal Scientist & CIFOR \\
\hline 8 & Rupesh Bhomia & Scientist & CIFOR \\
\hline 9 & Budi Wardhana & Deputy & Peatland Restoration Agency (BRG) \\
\hline 10 & Azwar Ma'as & Senior Lecturer & $\begin{array}{l}\text { Soil Science Department, Faculty of Agriculture, } \\
\text { Gadjah Mada University }\end{array}$ \\
\hline 11 & Agustinus Tampubolon & Research Scientist & $\begin{array}{l}\text { Forest Research and Development Centre (FRDC), } \\
\text { Forestry and Environment Research, Development } \\
\text { and Innovation Agency (FOERDIA), MoEF }\end{array}$ \\
\hline 12 & Sonny Mumbunan & Researcher & $\begin{array}{l}\text { Research Center for Climate Change, University } \\
\text { of Indonesia/Lead Environmental Economist and } \\
\text { Research Associate, World Resources Institute } \\
\text { (WRI) }\end{array}$ \\
\hline 13 & Haris Gunawan & Deputy & $\begin{array}{l}\text { Formerly at Peatland Restoration Agency (BRG)/ } \\
\text { Lecturer, University of Riau }\end{array}$ \\
\hline 14 & Ravi Prabhu & Director & Innovation and Impact, CIFOR-ICRAF \\
\hline 15 & Mark Reed & Professor & Scotland's Rural College (SRUC) \\
\hline 16 & Kristell Hergoualc'h & Senior Scientist & CIFOR \\
\hline 17 & Gusti Anshari & Professor & Tanjungpura University \\
\hline 18 & Muh Taufik & Lecturer & $\begin{array}{l}\text { Department of Geophysics and Meteorology, } \\
\text { Institut Pertanian Bogor (IPB) }\end{array}$ \\
\hline 19 & Myrna Safitri & Deputy Head & $\begin{array}{l}\text { Education and Socialization, Participation and } \\
\text { Partnerships, Peatland Restoration Agency (BRG) }\end{array}$ \\
\hline 20 & Marcel Silvius & $\begin{array}{l}\text { Country } \\
\text { Representative }\end{array}$ & Global Green Growth Institute (GGGI) \\
\hline
\end{tabular}




\begin{tabular}{|c|c|c|c|}
\hline No. & Name & Position & Organization \\
\hline 21 & Amy Duchelle & Team Leader & $\begin{array}{l}\text { Climate Change, Energy \& Low-Carbon } \\
\text { Development, CIFOR }\end{array}$ \\
\hline 22 & Herry Purnomo & Scientist & CIFOR \\
\hline 23 & Josi Khatarina & Coordinator & Terpercaya Secretariat/Inobu Team \\
\hline 24 & Yuti Ariani & $\begin{array}{l}\text { Postdoctoral } \\
\text { Researcher }\end{array}$ & Nanyang Technological University \\
\hline 25 & Dianto Bachriadi & Researcher & $\begin{array}{l}\text { Agrarian Resource Center (ARC)/ Pajajaran } \\
\text { University, Bandung }\end{array}$ \\
\hline 26 & Moira Moeliono & Senior Associate & CIFOR \\
\hline 27 & Siti Hamidah & $\begin{array}{l}\text { Head of the Study } \\
\text { Programme }\end{array}$ & $\begin{array}{l}\text { Tropical Forest Products, } \\
\text { Lambung Mangkurat University }\end{array}$ \\
\hline 28 & Abdul Manan & Chief Advisor & Ekonomi Kreatif Andalan (EKA), Riau \\
\hline 29 & Dharsono Hartono & CEO & PT. Rimba Makmur Utama (RMU) \\
\hline 30 & Adam Gerrand & Forest Officer & FAO, Jakarta \\
\hline 31 & Solichin Manuri & Senior Adviser & Daemeter Consulting \\
\hline 32 & Dyah Puspitaloka & Research Consultant & CIFOR \\
\hline 33 & Sera Noviany & $\begin{array}{l}\text { Sustainability } \\
\text { Compliance Head }\end{array}$ & Asia Pulp \& Paper (APP), Sinar Mas \\
\hline 34 & Diah Suradiredja & Policy Senior Advisor & Indonesia Biodiversity Trust Fund (KEHATI) \\
\hline 35 & Hasbi Berliani & Programme Manager & Sustainable Development Governance, Kemitraan \\
\hline 36 & $\begin{array}{l}\text { Dwi Rahmad } \\
\text { Muhtaman }\end{array}$ & CEO & Remark Asia Group \\
\hline
\end{tabular}




\section{Foreword}

Evaluating the success or failure of ecological restoration efforts within the initial phases of a project can help practitioners assess the situation and apply corrective measures if required. One possible way to conduct this assessment is by employing a criteria and indicators (C \& I) approach, where a set of identified C \& I can be utilized for easy and routine monitoring of applied interventions. Guided by overarching principles and supported by field testing, these C \& I can become an essential tool for peatland restoration. This is of particular importance now since peatlands have been identified as an important ecosystem in climate action and greenhouse gas (GHG) mitigation strategies. Rewetting to restore degraded and deforested peatlands offers a significant opportunity to reduce GHG emissions and generate local livelihood benefits by developing and promoting peatland friendly practices. Yet to galvanize support and demonstrate the success of peatland restoration efforts, an effective monitoring plan is a must. The proposed set of $C \& I$ is intended to fulfil this gap, providing a simple yet robust tool to monitor and report on both success and failures in peatland restoration. These $C$ \& I cover four key aspects of peatland restoration - biophysical, social, economic and governance to capture the range of topics and issues which impact upon it. A set of criteria and indicators that are relevant to the Indonesian context, easy to apply, responsive, representative, consistent, and sensitive would be highly useful. A helpful aid in decision-making processes, it is hoped these C \& I will be applied, adapted and adopted by personnel and agencies involved in peatland restoration, both within Indonesia and across the globe.

Rupesh K. Bhomia

Daniel Murdiyarso 



\section{Introduction}

The global extent of tropical peatlands and peat swamp forests is relatively small, yet these ecosystems play a critical role in the global carbon cycle. Peatlands cover just $3 \%$ of the Earth's land surface but being repositories of large quantities of carbon, this relatively small area stores twice as much carbon as all the world's forests put together. The carbon stored in peatland is equal in magnitude to the carbon stored within all the Earth's vegetation, or over half of the carbon stored within the atmosphere (Yu et al. 2010, Page et al. 2011, Dargie et al. 2017).

Peatlands are found throughout the tropics, making up an area between 33.4 and 57.8 Million hectares $(\mathrm{MHa})$ in size. Peatlands provide numerous ecosystem services, from regulating climate, floods and pollution abatement; to provisioning food, fibre, water and genetic resources; to supporting biodiversity, primary production and nutrient cycling; to socio-cultural uses, including recreation and education (Bonn et al. 2016).

Although peat accumulation rates are small ( 0.2-2.0 mm/year), peat deposits can grow to be several metres thick over millennia. Peat layers are composed of organic matter which has been stabilized by water-logged, anoxic conditions. The resulting peat can have carbon storage of more than $1000 \mathrm{Mg}$ of carbon per hectare, with values exceeding $7500 \mathrm{Mg}$ of carbon per hectare for exceptionally thick (i.e., more than $12 \mathrm{~m}$ ) peat layers (Jaenicke et al. 2008). These ecosystems therefore hold the largest carbon stocks per unit area of any terrestrial ecosystem on earth.

Despite their importance, peatlands are threatened by anthropogenic activities, and in recent decades peatlands have been degraded, drained and burned, mainly for agricultural and forestry purposes, contributing about 2 billion metric tons of carbon dioxide per year to the atmosphere. High rates of degradation, caused by drainage and removal of vegetation, have transformed many of them from being carbon sinks to being sources of greenhouse gases (GHGs). The degradation of peatland also compromises its ability to provide ecological goods and services; peatlands deliver a range of ecosystem services that contribute to human well-being, including climate regulation, water purification, recreational and educational opportunities, and tourism. Recognizing these important attributes - provision of ecosystem services and exceptional ability to slowly sequester and store carbon - countries are taking actions to prevent degradation and setting goals to restore degraded peatlands. 


\section{Peatland restoration in Indonesia}

Indonesian peatlands and peat swamp forests cover an area of $21 \mathrm{Mha}$, representing around $36 \%$ of the world's tropical peatlands. However, much of Indonesia's tropical peatland area has been degraded since the 1980s through deforestation and drainage, mainly for forestry and agriculture purposes (Warren et al. 2017). Under existing global commitments to reduce GHG emissions, Indonesia's climate change mitigation efforts aim to prevent further degradation of peatlands and focus on strategies to conserve and restore these peatlands. Restoration of the degraded peatlands could be an important step to stall any further loss of these ecosystems. Peatland restoration entails deliberate actions that initiate or accelerate the recovery of degraded peatland to a former better state. It involves measures to change ecosystems that have been impoverished, damaged or destroyed due to human activity, reverting them to a state similar to, or as near to, their natural state as possible, as well as re-establishing some of their ecological processes and functions (Dinesen and Hahn 2019).

Peatland restoration can play a pivotal role in fulfilling international and national obligations and safeguarding important ecosystem services for society. The Government of Indonesia has identified over $2 \mathrm{Mha}$ of degraded peatlands for restoration in order to meet the targets of its nationally determined contribution (NDC), made under the Paris Agreement. With this in mind, the Indonesian government has made a strong commitment to peatland conservation and restoration through the enactment of Government Regulation No. 71/2014 (revised by Regulation No. 57/2016). Article 23 of this regulation lays out criteria for determining the status of a peatland ecosystem on the basis of its biophysical attributes. For instance, peatland ecosystem can be considered degraded when: it is subjected to artificial drainage; pyrite or quartz sediment underneath the peat layer is exposed; land cover in the peatland ecosystem is reduced; and/or ground water level in the peatland is altered/ lowered (lower than $40 \mathrm{~cm}$ below the peat surface).

Overall responsibility for regulating peatland restoration lies with the Indonesian Ministry of Environment and Forestry, whereas actual restoration work is coordinated by the Peatland Restoration Agency (Badan Restorasi Gambut, BRG). Planning of restoration actions in Indonesia often includes mapping peatlands' extent, depth, hydrology, land status (land tenure, protected areas), biodiversity, habitat condition, management status and vegetation cover, including the degree of degradation (drainage canals, fire scars, historical fire incidents), as well as defining other important characteristics to inform restoration actions (e.g., slopes).

Priority areas for restoration activities include: (a) areas burnt in 2015, (b) peat domes, and (c) peatlands with drainage systems (canals). Guided by holistic efforts that include rewetting, revegetation and revitalization (the 3Rs), the Peatland Restoration Agency has developed a series of specific steps for peatland restoration, including planning and monitoring (Figure 1). These steps are underpinned by strategies that target future sustainable land use and management, social justice, livelihoods, governance and conflict resolution.

The Peatland Restoration Agency (BRG) has undertaken restoration in seven provinces: Riau, Jambi, South Sumatra, West Kalimantan, Central Kalimantan, South Kalimantan and Papua. Interventions are aimed at restoring and maintaining peatland functions and services. These activities include rewetting drained peatlands (by disabling the drainage systems through back-filling and canal blocking), revegetating the landscape (planting appropriate native vegetation), and preparing peatlands without using fire (Pembukaan Lahan Tanpa Bakar, PLTB). The Agency supervises, facilitates, assists and coordinates peat rewetting both within and outside of concession areas. 


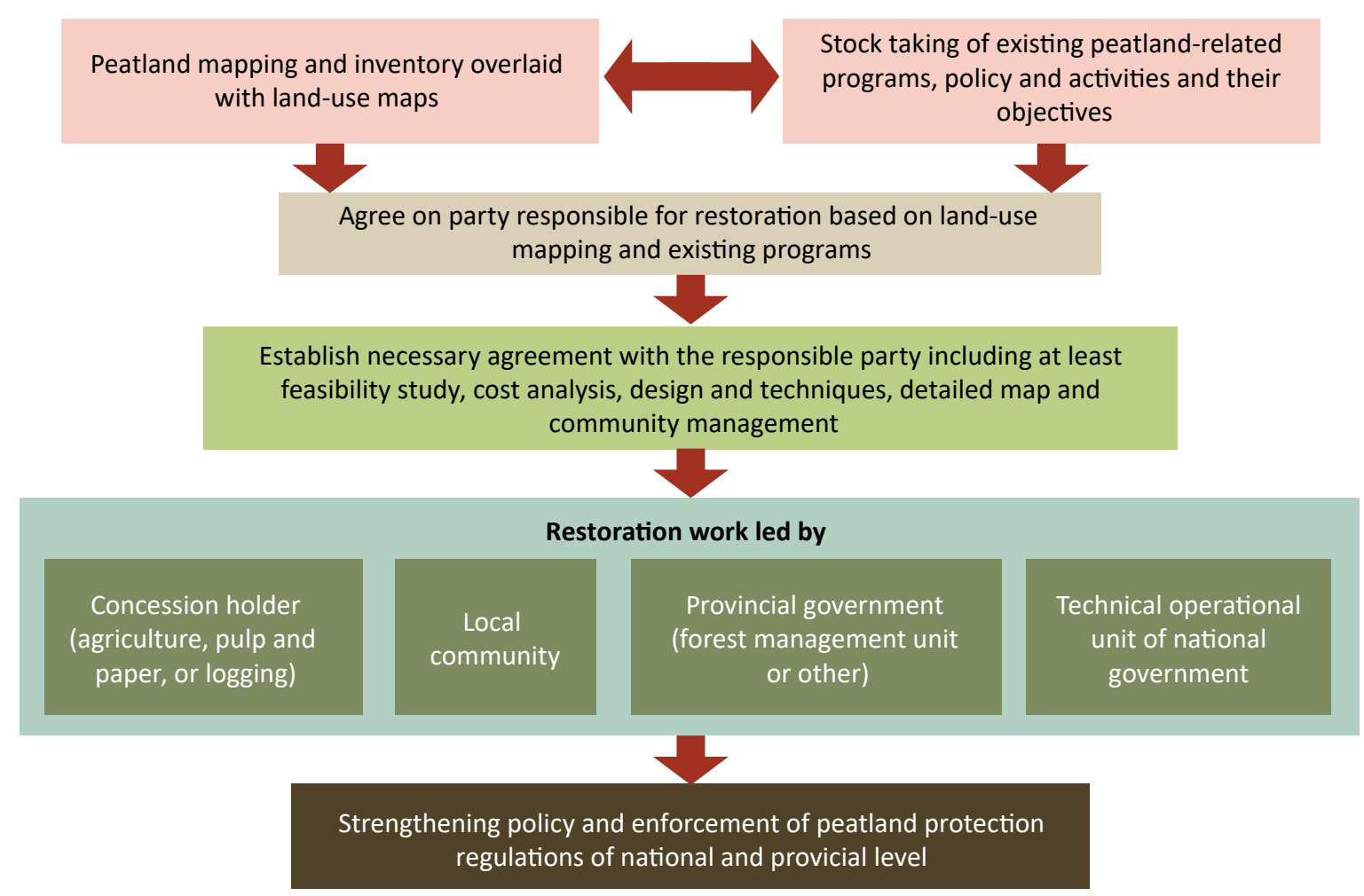

Figure 1. Step-by-step approach to peatland restoration, as undertaken by Indonesia's Peatland Restoration Agency (Wardhana, 2016)

According to the Peatland Restoration Agency, criteria are useful for providing relevant information and measuring restoration progress over time, while indicators are useful to measure project impacts, outcomes, outputs and inputs during implementation, as well as to assess progress towards project objectives. The Peatland Restoration Agency also highlighted certain challenges associated with monitoring, including costs, methods, time, usability, reliability, and the effectiveness of adjustments and corrective actions.

Through strong commitment and collaboration, the Agency has undertaken restoration activities with support and participation of stakeholders like universities, civil society organizations (CSOs), local government and communities. Such restoration interventions, in the form of water management improvement, have contributed to a reduction of approximately 285 million tons of $\mathrm{CO}_{2} \mathrm{eq}$ emissions as determined by a water-level monitoring database (SiMATAG-0.4m). To maintain such achievements, a reliable and practical set of criteria and indicators to monitor and assess peatland restoration will be highly useful.

The Peatland Restoration Agency contends that restoration works best when it is carried out by taking the Peatland Hydrological Unit (PHU) into consideration, or following a landscape approach. Representatives of the Agency also believe that developing local peat-friendly commodities and incentives could create harmonious living conditions in peatland areas; an example of this is wet agriculture systems (paludiculture), which could allow sustainable livelihood avenues without degrading peatlands. Practically, criteria and indicators are important for defining, understanding and sharing what good peatland restoration is; assessing, measuring and monitoring progress; and communicating and reporting on that progress. 


\section{Advances in peatland restoration monitoring approaches}

As with any ecosystem restoration, peatland restoration needs to be underpinned by assessment and monitoring efforts that allow for an adaptive approach. This adaptive approach is based on an iterative process of learning from previous actions and allows for course correction if/when interventions are not leading to expected outcomes (Herrick et al. 2006). Restoration assessment and monitoring (Figure 2) can inform design, strategy, site selection and management approaches, and improve restoration efforts through adjustments (FAO 2020). Robust peatland monitoring, following sound science-based practices, would also enhance transparency and accountability under the UNFCCC framework, to fulfil reporting requirements and enable access to additional sources of funding.

Peatland monitoring methods can differ depending on the extent of the peatland, the nature of anthropogenic disturbances, planned restoration interventions, objectives, accessibility, available resources and the parameters of environmental targets. An ideal approach would ensure that emissions and emission reductions are measurable, reportable and verifiable, while also providing information on the delivery of other peatland ecosystem services. Ideally, peatland monitoring would form part of national land monitoring and reporting system(s) and build upon them.

Within Indonesia, peatland monitoring tools, approaches and experience have advanced in leaps and bounds in recent years. To support monitoring, the Peatland Restoration Agency has developed the Peatland Restoration Information and Monitoring System (PRIMS) and Peat Groundwater Level Monitoring System (Sistem Pemantauan Air Lahan Gambut, SIPALAGA) to update and report on the

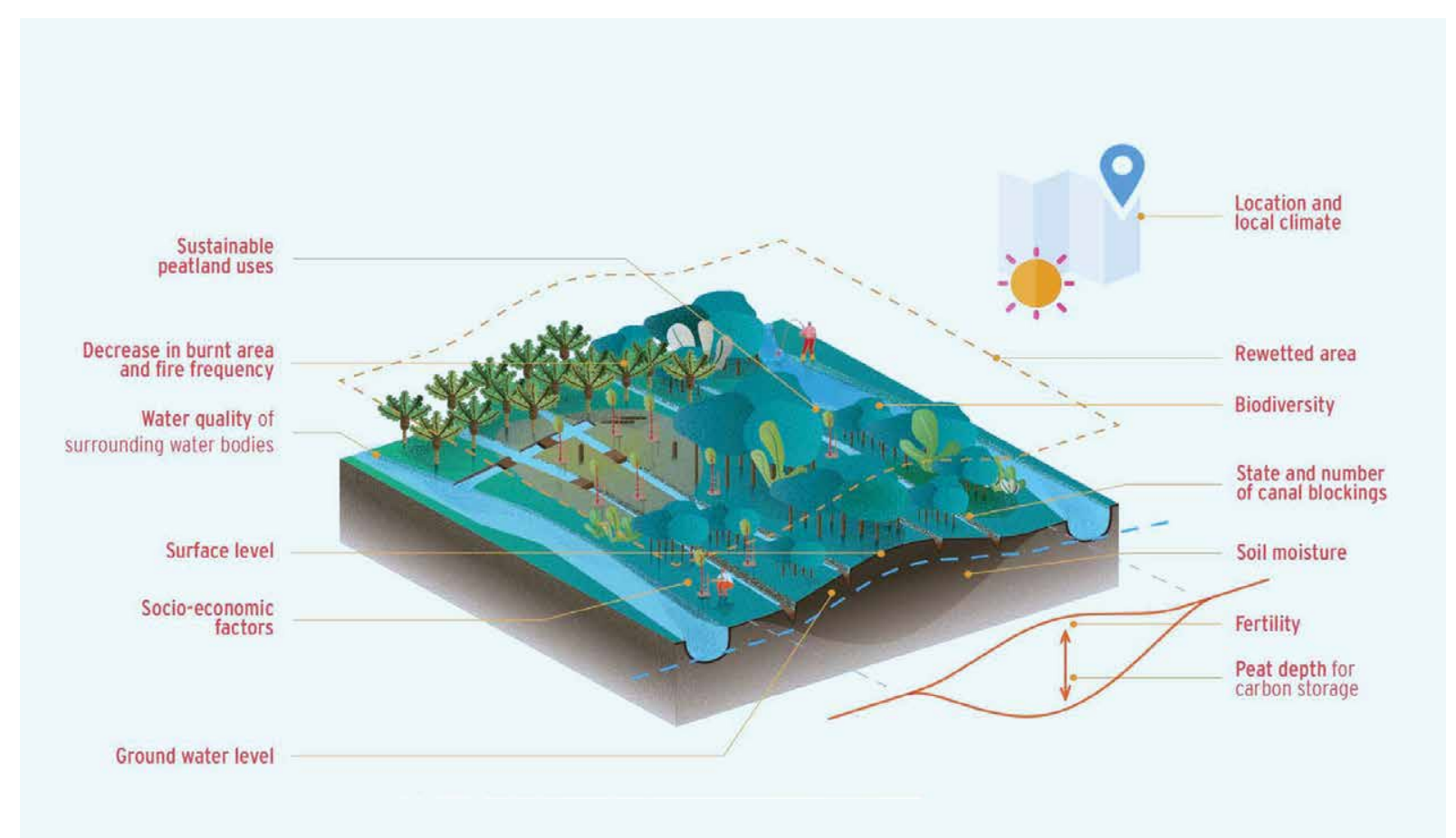

Figure 2. Key parameters to be monitored to achieve holistic peatland restoration (FAO 2020) 
progress of peat restoration activities transparently and reliably, to provide timely feedback to land managers and policymakers, and to facilitate coordination across provinces and institutions.

PRIMS is a prototype web-based mapping system. Although still under development, it has key features that can both provide insight into restoration activities, peat degradation indices, peat emission and fire hotspot monitoring, and aide the assessment of restoration efforts like canal blockings and backfilling, revegetation and the economic revitalization of communities. Existing monitoring approaches and mechanisms to measure the success of peatland restoration in Indonesia include two integrated systems:

1. The $0.4 \mathrm{~m}$ Peat Groundwater Information System (Sistem Informasi Muka Air Tanah Gambut $0.4 \mathrm{~m}$, SiMATAG-0.4 m) which monitors groundwater level in peatlands (concession areas only) and serves as a data repository.

2. The System for Earth Observation Data Access, Processing, and Analysis for Land Monitoring (SEPAL), which monitors changes in vegetation and soil moisture, and records when such changes occurred (by date, month and year).

Some gaps in the management and restoration of Indonesia's peatlands are evident. These include the need to: develop an integrated monitoring system for peatland restoration; improve the information sharing system; take a cascading approach, from general to specific; and ensure reliable methodologies to verify soil moisture and to monitor GHG emissions. To address these gaps, the Ministry of Environment and Forestry and partners have deployed several strategies, including efforts to complete a peatland ecosystem inventory and establish a groundwater monitoring system in non-concession areas. These efforts will be supported by an information system for peatland protection, management and decision support (called SiPPEG). Alongside these efforts, civil society and non-government organizations (CSOs and NGOs) are also developing more grassroot (e.g., Pantau Gambut) and community-based approaches (e.g., CIFOR's CO-PROMISE).

Despite all these efforts, several major data gaps remain. Monitoring biophysical parameters, so as to understand the hydrological aspects of peatlands, proves particularly challenging. Likewise, in the socio-economic sphere, research into the feasibility, scaling-up and scaling-out of a peatfriendly economy as well as opportunities to establish peatland-derived payments for the ecosystem services, is especially urgent. Multi-stakeholder participatory development research - particularly that which addresses information gaps around the social and governance aspects of peatland use and restoration - is also needed.

Peatland-focused practitioners and institutions need tested protocols to determine the success or failures of peatland restoration objectively. This requires progressive indicators to monitor the continuation of restoration efforts, as well as to act as foundations upon which the restoration actions of all stakeholders, at all levels, are built. Four important pillars must be considered when developing criteria and indicators for tropical peatland restoration - biophysical, social, economic and governance. The criteria and indicators currently used by the Peatland Restoration Agency concentrate on biophysical aspects, while overlooking other key pillars. This could be due to difficulties defining indicators that relate to other aspects, however, without a holistic overview it is impossible to ensure restored peatlands become both healthy and well-functioning ecosystems, and support the livelihoods of local communities.

Bio-physical indicators - relating to the ecological, hydrological and fire aspects of peatland - allow stakeholders to monitor the restoration and maintenance of peatland hydrologic units' integrity, as well as fire risk reduction; social indicators - relating to social networks, equity, trust and justice - allow stakeholders to determine the extent of democratic processes and participation, conflict resolution and volunteerism, which are all important for social solidarity; economic indicators enable the monitoring of existing incentives and new livelihood options in peatland landscapes; and 


\section{Box 1. A demand-driven approach to identify peatland monitoring principles, criteria and indicators}

The exercise of identifying principles, criteria and indicators for peatland restoration monitoring took a demand-driven approach. As it was based upon the Peatland Restoration Agency's expectations, the following points guided the development of these principles, criteria and indicators:

- The restoration of degraded peatlands takes decades, and needs long-term, comprehensive and continuous monitoring based on scientifically robust criteria and indicators.

- It is important to ensure continuous knowledge exchange, through discussing scientific ways to use criteria and indicators for monitoring and evaluation.

- Although the monitoring approach and use of remote sensing technology are still under development, some indicators require field data immediately.

- The Peatland Restoration Agency will benefit greatly from the development of principles, criteria and indicators to monitor biophysical, social, economic and governance related aspects of peatland restoration, to ensure a holistic overview of ongoing restoration and to identify possible corrections where required.

- A critical aspect of peatland monitoring is improving village-level governance; this requires activities like the Peatland Restoration Agency programme that builds the governance capacity of community groups and villages, the Peat Care Village (Desa Peduli Gambut, DPG).

governance indicators mean stakeholders can explore what policies are needed and are appropriate at local, provincial and national level for successful implementation.

Taking a balanced approach that covers these four aspects means restoration targets can be adequately quantified and success can be measured holistically. With this in mind, CIFOR and the Peatland Restoration Agency, with the support of various partners, organized a series of webinars ${ }^{1}$ to explore and identify scientifically robust, reliable and practical criteria and indicators for peatland restoration monitoring under these four pillars. The webinar series was designed to further develop the capacity of key technical and policy personnel from various Indonesian government agencies and departments with mandates to protect and restore peatlands while ensuring the well-being of dependent communities. The online workshops facilitated consultation between key stakeholders to identify an initial set of criteria and indicators that could assess restoration success, while being contextually relevant to the areas where they are applied.

At the end of this exercise (expected to be completed in late 2021), the main outputs will be:

- A Framework and identified set of restoration principles, criteria and indicators

- Clarity on key indicators and a practitioner's manual for implementing $C$ and I approach towards peatland restoration monitoring

- Roles and responsibilities determined for all participating agencies and experts in identifying, testing and implementing criteria and indicators

- Sources of financing identified to secure monitoring activities over time

- Increased capacity among key technical and policy personnel in relevant Indonesian government agencies and departments 


\section{Principles, criteria and indicators for peatland restoration}

\subsection{Identification}

The principles, criteria and indicators approach has been designed by CIFOR and the International Tropical Timber Organization (ITTO) in the context of assessing success and failures towards sustainable forest management (Prabhu et al. 1999). This approach has been used by various agencies and international organizations to monitor progress towards pre-defined goals. This suggests that the newly-developed peatland restoration principles, criteria and indicators can be linked with peatland restoration guidance being prepared by the Ramsar Convention and other international processes where sustainability indicators have been developed to inform peatland restoration. Progress against the UN Sustainable Development Goals targets is assessed using a global indicator framework that includes 231 unique indicators, for example; while the Millennium Ecosystem Assessment uses both biophysical and socio-economic indicators to collect data for assessment and decision making.

The process of identification of criteria and indicators must capture the reality of restoration outcomes. A consultative participatory process of deciding upon them helps to smooth out any context-specific differences between human-ecological sites, and allows decision makers to interrogate the legitimacy, sustainability and desirability of local aspirations for those sites, as well as determine and modify planned interventions.

Fundamental to the concept is the rule that no single criterion or indicator by itself constitutes a complete measure of restoration. An individual criterion or indicator needs to be considered within the context of other criteria and indicators in the system. It is useful to think of these criteria and indicators as information nodes on areas of concern, which together provide a full picture of the state of peatlands and restoration success trends at the hierarchical level (Figure 3).

In this hierarchy, principles are fundamental truths, elaborated on through criteria, which are the intermediate points into which information (provided by indicators) can be integrated, and around which an interpretable assessment can be formed. Indicators and verifiers define what information is delivered to evaluate the criteria. While indicators are variable components used to infer the status of a particular criterion, verifiers contain data or information that enhances the specificity or ease of assessment of an indicator.

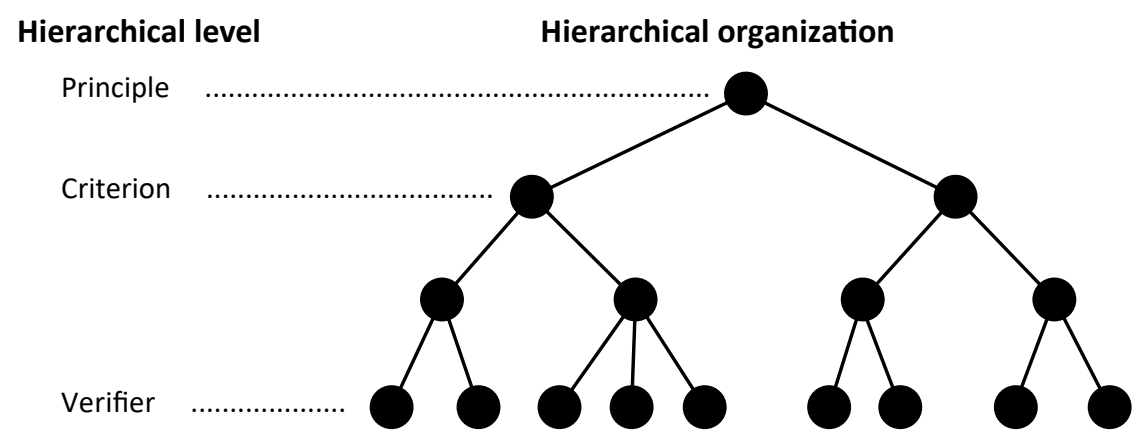

Figure 3. Hierarchical organization of principles, criteria and indicators (Pokorny and Adams 2003) 
As well as the hierarchical structure of the approach, it is also necessary to consider the following practical issues when developing principles, criteria and indicators:

- Principles, criteria and indicators are tools, therefore not fixed or set in stone

- All stakeholders within the landscape should be considered as users of the principles, criteria and indicators

- Information will be collected from across the landscape, so it is important to consider how this information will be of value to diverse stakeholders

- A principles, criteria and indicators approach can be expensive to implement, so it is important to consider costs

- Principles, criteria and indicators can be difficult to understand, so it is important for them to be practical

Before establishing principles, criteria and indicators, it is important to first establish the goal and objectives of a specific site and programme. Principles, criteria and indicators should aim to change behaviours and promote learning, link to a theory of change, and respond to the objectives of a specific location (theory of context or place); they also need evaluation and assessment, and should therefore be easily understood and applied by the target audience.

There are two different types of principles, criteria and indicators - generic and localized. Generic means principles, criteria and indicators are not specific to any site, and can be modified and customized to comply with local conditions. Every site will have different indicators and verifiers. Generic principles, criteria and indicators are adaptable to all types of tropical peatland situations, and act as an operational 'mother' set. A lot of the generic principles should apply across all peatlands, and most of the criteria will be similar; however, when we consider indicators and verifiers, divergence can be expected, both between peatlands and other terrestrial systems, and among peatlands. At that level, site specificity can come into play.

Another key consideration is the suitability of principles, criteria and indicators to the restoration efforts in question. Prabhu et al. (1999) highlight nine things to be considered when determining this suitability:

- Relevant

- Reliable

- Related logically to the assessment goal

- Precisely defined

- Diagnostically specific

- Easy to detect, record and interpret

- Adequate response range to changes in levels of stress on the peatland governance, ecological, economic or social systems

- Provide a summary or integrative measure over space and or time

- Appeal to users

As peatland restoration issues are complex, significant learning took place during the webinar series. To finalize the principles, criteria and indicators for peatland restoration it was suggested that:

- Science is important, but the practical use of existing science/knowledge is even more important

- Vast literature and experience exist, but innovation is critical

- Solutions that address real world challenges should be promoted to achieve the targets for peatland restoration

Development of principles, criteria and indicator frameworks should therefore keep a clear focus on achieving identified targets and these should be easy to communicate. While principles can be overarching and broad, some key features for criteria and indicators are that:

- They should be purpose dependent, i.e., their interpretation depends on the specific purpose of the issue in question.

- The process behind developing them is iterative.

- They should act as communication tools, helping to communicate changes and progress towards specific targets, while also supporting and guiding policy decisions. 
During the process of developing principles, criteria and indicators, it is important to be mindful of common pitfalls and mistakes that can pose a barrier to achieving end goals. Pitfalls to be avoided include: over-reliance on single indicators (or indices); reporting indicators without contextual data to aide interpretation; accurate indicators that nobody can measure; and monitoring without local community benefits.

Consistency, both in terms and their meanings, is equally important when determining criteria and indicators; this is because different terms measure and report different indicators in different ways, compromising meaningful synthesis. This can pose serious issues further down the line, as good and effective policies are a result of synthesized evidence, rather than individual studies. Criteria and indicators that are developed without local community engagement are also less likely to result in behaviour change than those developed with the active participation and consultation of key stakeholders. That said, each site will vary in terms of what its 'local community' looks like; an understanding of the entire set of stakeholders within the landscape is thus a helpful first step. In the context of peatland restoration, and for a meaningful set of functional criteria and indicators, there should be agreement around core indicators that can be measured by most monitoring programmes in comparable ways.

\subsection{Consultative process}

CIFOR organized a series of online workshops inviting a diverse group of stakeholders, including policymakers, practitioners and academics, to explore criteria and indicators for tropical peatland restoration. Four such workshops took place, in which national and international representatives of government, universities, non-government and research organizations discussed key aspects of peatland restoration and deliberated on practical ways to monitor restoration success. In total, these webinars involved 20 sessions with 50 speakers, 18 moderators facilitating 11 discussions, and 827 participants across many countries. The webinar series was organized into four parts (Figure 4) to cover all important aspects that underpin the long-term sustainability of peatlands and that are crucial for successful restoration. After exploring the general setting of the 'peat-landscape', existing issues and relevant actors, four key pillars formed the basis of separate webinars before discussions were synthesized.

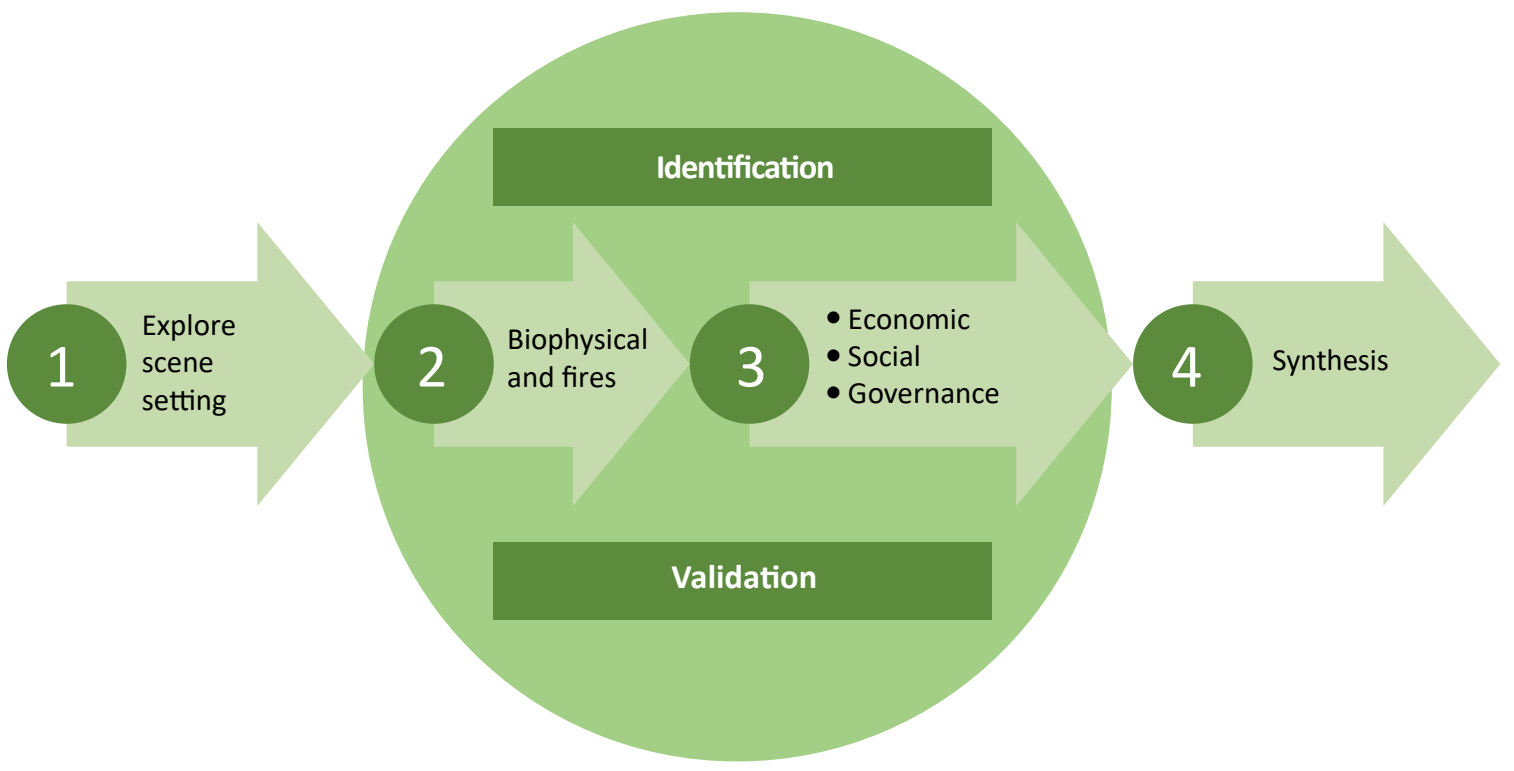

Figure 4. Four-part organization of the webinar series to identify principles, criteria and indicators for peatland restoration 
The process of identifying principles, criteria and indicators for peatland restoration began with the largest aspect - biophysical - which includes vegetation, peat properties, hydrology, greenhouse gas emissions and fires. The abundant information available on these diverse aspects required grouping or classification. Economic, social and governance aspects - which are more difficult to quantify were then identified from experience at both project and programme levels. In the following section, we present a summary of discussions that took place in the consultative workshops, as a starting point in developing principles, criteria and indicators for peatland restoration.

\subsection{Biophysical aspects}

Guided by the overarching principle 'Wet and vegetated peatlands without any risk of drainage or deforestation', which was generally accepted across stakeholders regardless of their background and role, three criteria and associated indicators were identified by webinar participants/ stakeholders. These indicators were based upon high-quality existing data, official and academic data and evidence, and credible sources of information. The criteria and indicators identified through the webinar discussion is presented in Table 1.

Of the indicators proposed, the hydrological indicators were deemed most foundational, because of the way that they regulate climatic and biodiversity aspects. Fire susceptibility was also identified as an immediate response risk when peat hydrology is altered. The need to clearly define and measure the water table with approaches that are less susceptible to error or misinterpretation was also highlighted by stakeholders in the webinar series. It was generally accepted by webinar stakeholders that indicators would be different for degraded and restored peatland, and as such, indicators must be adjusted regularly according to the level of degradation and success of restoration. Indicators are also weather dependent, in connection with seasonality patterns. In many cases it is both desirable and essential to involve the local community in data capture; some of the data to be collected requires a wide range of spatial distribution and technology. Local people can be involved in validation by integrating science and local knowledge.

Table 1. Identified criteria and indicators relating to biophysical aspects of peatlands.

\begin{tabular}{ll}
\hline Criteria & Indicators \\
\hline Ecosystem /land cover functionally intact & Dominant land use \\
\cline { 2 - 2 } & Local species \\
\cline { 2 - 2 } Restored hydrology & Commercial species \\
\cline { 2 - 2 } & Water table \\
\cline { 2 - 2 } & Dryness index/soil moisture \\
\hline Quality of peat & Reduced subsidence \\
\hline & Peat maturity \\
\cline { 2 - 2 } & Peat depth \\
\cline { 2 - 2 } & Heterotrophic respiration (GHG emissions) \\
& Organic matter content \\
\hline
\end{tabular}

\subsection{Economic aspects}

Economic indicators for peatland restoration were underpinned by the overarching principle 'A viable and sustainable peatland-based economy'. Under this principle, participants identified five criteria and several indicators for each criterion to capture the economic aspects of peatland restoration. 
For restoration efforts to be successful, economic approaches that can reduce anthropogenic pressures and promote sustainable livelihood alternatives are needed. Monetizing the environmental services provided by protected and restored peatlands could, therefore, be a way to convince society that peatland restoration is economically viable; this provides far greater benefits than how peatland is presently recognized or valued. These considerations were taken into account while identifying economic indicators (Table 2), and due emphasis was given to the importance of maintaining analytical soundness and measurability of indicators. Criteria and indicators were also determined by recognising their connection with policies that may underpin favourable economic outcomes for the people where peatland restoration interventions are undertaken. Stakeholders highlighted the great need for sensitivity around livelihood issues, and reconciling restoration efforts with the value addition potential of new sustainable business development for local communities. As such, robust economic valuation methods for environmental services, financial schemes and integrated policy all play crucial roles, when resource availability, livelihoods and community well-being are to be integrated into local policies governing resource access and use. In the case of peatland restoration, the identified criteria and indicators are meant to provide a method to quantify the existing situation and determine progress from that initial assessment.

Table 2. Identified criteria and indicators relating to economic aspects of peatlands.

\begin{tabular}{|c|c|}
\hline Criteria & Indicators \\
\hline \multirow[t]{8}{*}{ Sustainable and just value chains } & Promotion of local products \\
\hline & Rate of product innovation \\
\hline & Product certification/standardization \\
\hline & Provision of raw material \\
\hline & Processed goods/value addition \\
\hline & Technology used in production \\
\hline & Wetland-based small and medium enterprises (SME) \\
\hline & Wetland-dependent side industries \\
\hline \multirow[t]{3}{*}{ Economic incentives for peatland restoration } & Access to finance \\
\hline & Access to markets \\
\hline & Return on invested capital \\
\hline \multirow[t]{6}{*}{ Wealth } & $\begin{array}{l}\text { Revenue or proportion of sustainable products/services } \\
\text { generated from wetland-based businesses }\end{array}$ \\
\hline & Household income \\
\hline & Annual household savings \\
\hline & Contribution to gross domestic product (GDP) \\
\hline & $\begin{array}{l}\text { Sustained long-term revenue growth/prevention of } \\
\text { productivity loss }\end{array}$ \\
\hline & Avoided health costs \\
\hline \multirow[t]{4}{*}{ Economic valuation of services } & Cost savings due to avoided environmental disasters \\
\hline & Value of avoided emissions \\
\hline & Investment into avoided emissions \\
\hline & Value of ecosystem services \\
\hline \multirow[t]{3}{*}{ Human resources } & Job/workforce creation due to wetland-based enterprises \\
\hline & Improvements in human capital \\
\hline & Community dependency on wetland-based businesses \\
\hline
\end{tabular}




\subsection{Social aspects}

'Community well-being and equity is widely demonstrated' was the overarching principle under which webinar stakeholders identified three criteria for the social aspects of peatland restoration. Stakeholders observed that appropriate access to and availability of social data/information is crucial to disentangle the complex social issues surrounding peatland restoration, and therefore appropriate efforts must be made by the respective actors, despite the challenge of getting good and reliable data. The role and involvement of local communities in implementing restoration activities was seen to be particularly important by all participants. However, it was also seen as challenging to involve the community in peatland restoration activities, because such activities sometimes conflict with the peatland-dependent economic activities that community members are involved in. Development of meaningful social criteria and indicators (Table 3 ) therefore involved mapping social capital, welfare and cohesiveness, and identifying indicators around elements like gender equality, power sharing, social networking, etc.

Webinar discussions also recognized the importance of proxy criteria and indicators to capture the complexity surrounding social norms, culture, religious beliefs and community preferences - aspects that could be important for peatland restoration interventions. Good proxies are based on robust and reliable data and often combine field data with existing data from government documents. The role of local government institutions, as well as grassroot organizations involved with local communities was also felt to be an important ingredient for peatland restoration success.

Table 3. Identified criteria and indicators relating to social aspects of peatlands.

\begin{tabular}{ll}
\hline Criteria & Indicators \\
\hline Social capital & Gender equality \\
\cline { 2 - 2 } & Power sharing \\
\cline { 2 - 2 } & Social networks \\
\hline Social welfare & Land ownership and tenure rights \\
\hline Social cohesiveness & Water and food security \\
\cline { 2 - 2 } & Access to education \\
\hline & Access to health services \\
\hline & Out-migration \\
\hline & Benefit sharing \\
\hline
\end{tabular}

\subsection{Governance aspects}

The proposed overarching principle for governance was 'Just, fair and strong governance at all levels'. Three criteria were identified under this principle, with several associated indicators. Governance is a broad topic that looks beyond social-political aspects and covers finance and economics, along with the environment, political governance, and governance at both landscape and jurisdictional level. As such, governance-related criteria and indicators (Table 4) do not only consider outcomes, but also attempt to capture the process.

Webinar stakeholders highlighted that transparency and consultation are two important principles in governance; as such, using a principles, criteria and indicators approach is one method of stakeholder communication through which good governance can be achieved. As every stakeholder group is different, with different ideas, priorities and needs, achieving a common understanding between stakeholders is challenging. Stakeholder groups need to have equitable positions throughout the decision-making process. A starting point for this is clear, government-granted rights for all stakeholder groups, including local communities. 
Table 4. Identified criteria and indicators relating to governance aspects of peatlands.

\begin{tabular}{ll}
\hline Criteria & Indicators \\
\hline Decision-making processes & Level of participation \\
\cline { 2 - 2 } & Level of transparency \\
\cline { 2 - 2 } Enabling instruments & Role of women \\
\hline & Level of accountability \\
\hline & Formal and informal institutions \\
\cline { 2 - 2 } & Formal regulation \\
\hline Customary laws \\
\hline Adaptive capacity to change & Conflict resolution \\
\hline & Rule of law \\
\hline & Natural resource governance \\
\cline { 2 - 2 } & Traditional/local knowledge \\
\hline & Institutions \\
\hline & Regulatory framework \\
\hline
\end{tabular}

Also highlighted as key to good governance were participation and social engagement. Social engagement in peatland restoration is especially important, because as well as a conservation value, restoration has social-economic, including cultural, value. Workshop participants discussed the possibility of governance-related criteria and indicators to cover profitability and productivity in supply chains, the reduction of social conflicts and the protection of human rights, including indigenous land rights. Some of these are already included in the list of socially-related criteria and indicators (Table 3).

\subsection{Verification}

Following synthesis and analysis of all the principles, criteria and indicators identified through the webinar series, the next stage of the process is verification. This includes identifying relevant verifiers and 'on the ground' field testing, with support from relevant institutions and organizations working in the peat landscape. Verification needs to be cost-effective and affordable; quick, simple and understandable (this is key so different evaluation teams can effectively apply and produce consistent results); and transparent and plausible, so results are acceptable and reproducible. All principles, criteria and indicators need to be tested, and there needs to be a common understanding of the differences between terms like input, process, outputs, outcomes and impact.

After the verification process is complete and criteria and indicators have been finalized, monitoring and assessment must continue on an ongoing basis to ensure uniform application across the landscape, and across different sites and communities where peatland restoration is taking place. Workshop participants highlighted some important points to be kept in mind during the ongoing monitoring and assessment phase:

- Multi-criteria analysis is important so progress can be measured against objectives: indicators need to be integrated into criteria and then into principles in a way that results in a mutuallyagreeable overall score for each objective

- Clear standards/norms and monitoring knowledge are required

- Representativeness is important in scoring and assessing, as well as the awareness that even sustainability is locally and culturally defined

- Transparency is maintained

- Assessment is a part of evaluation, and critical for adaptive co-management (learning for improvement) 


\section{Synthesis}

The principles, criteria and indicators approach present a practical way to define, assess, monitor and communicate peatland restoration efforts. Workshop participants (Figure 5) considered it important to strike a balance across different sustainability dimensions (i.e., economic, social, environmental and governance). The criteria and indicators they identified are intended to be oriented towards target audiences, so they remain relevant and meaningful to the key actors involved at all levels of peatland restoration, including government bodies, community organizations etc.

While discussing biophysical aspects, webinar stakeholders identified a trade-off between the viability of the principles, criteria and indicators approach and the need for highly accurate data. The measurement of some indicators requires expensive equipment, while other indicators, like water table levels and water content, are easily measured by the local community. Stakeholders discussed the possibility of a quick-and-easy method to quantify soil moisture so that in future local communities are able to measure this.

The economic aspects of peatland restoration are largely attached to the environmental goods and services provided by peatland. As such, the valuation of benefits provided by peatlands was considered to be particularly critical. Many of the proposed criteria and indicators relate to cost savings and the value of avoided environmental disasters and emissions, as well as the value of ecosystem services, sustained and long-term growth, returns on investment capital, economic security, infrastructure, community well-being, industry, market access and technology. Education and awareness were also considered to be important factors; stakeholders agreed that the bottomup approach needed to solve peatland challenges requires close cooperation with local communities, and that well-coordinated collaboration with and between communities achieves results. A key goal is to make sure peatland-connected communities have secure livelihoods by solving both the current

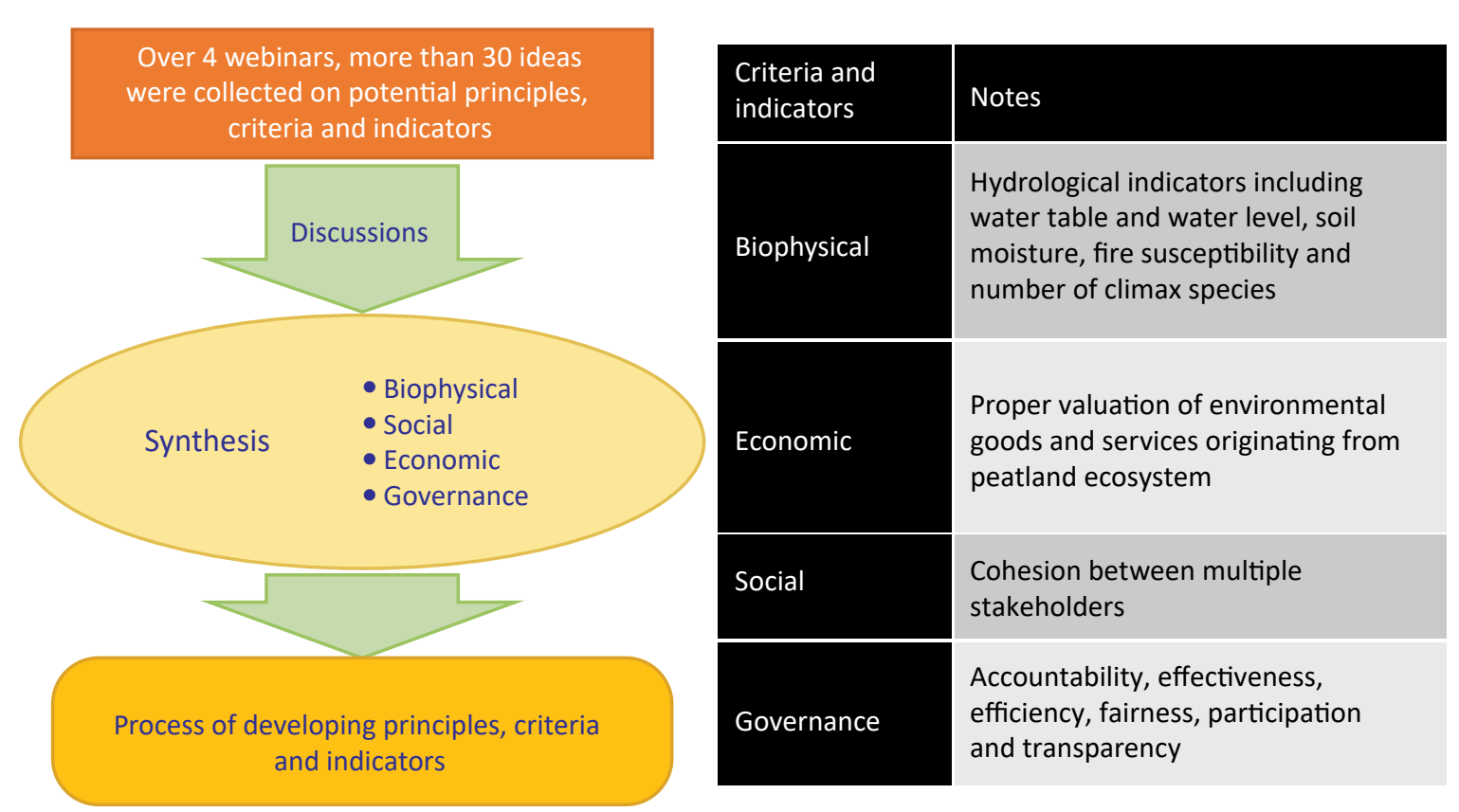

Figure 5. A synthesis of the peatland restoration webinar series and main learning points 
and long-term problems associated with this. This will also require the involvement of relevant industry bodies like the Roundtable on Sustainable Palm Oil (RSPO) and Indonesian Sustainable Palm Oil (ISPO) Certification, who are instrumental in certifying and accrediting palm oil, which could originate from concessions for oil palm plantations established on peatlands.

The social aspects of peatland restoration are complex and require participatory approaches to address that complexity. At a higher level, community well-being and equity need to be widely demonstrated in peatland restoration interventions and activities. It is vital to look at social capital, including indicators around gender equality, power sharing, empowerment and social networking (including connectivity). Social networking analysis can provide an understanding of information flows, power dynamics in decision-making processes, and who makes decisions. The importance of data availability and relevance cannot be overstated. Many of the complex issues cannot currently be resolved due to a lack of data access or availability; thus there is a need to have relevant data available for future indicators to be useful.

From the perspective of developing governance criteria and indicators, it was seen particularly important to have a common understanding on what the final goal is and a pathway towards that goal. Webinar attendees highlighted that this should involve a multi-stakeholder and participatory process to foster cooperation and collaboration among all actors. Governance criteria and indicators are to include aspects of transparency, public accountability and commitments, the recognition of human rights, local wisdom and indigenous and local people's rights. 


\section{Way forward}

During the consultative process some other salient points and cross cutting ideas in connection to principles, criteria and indicators also emerged. These points need be kept in mind for successful implementation of criteria and indicators in peatland restoration monitoring. For instance, webinar stakeholders generally accepted that gender equality cuts across all aspects, as we can see when looking at the roles of women in generating household income or their levels of participation in public debates. Indicators, therefore, must be verified across the different pillars, as well as within a particular set.

Also, peatland restoration practice could be modified across geographic locations depending on specific biophysical challenges and social contexts. In this case, the sets of criteria and indicators may also need to be modified, and testing may be required in such cases to optimize the effectiveness of criteria and indicators. Stakeholders sharing the same definitions for peatland restoration terms is also key in developing criteria and indicators, like definitions for 'full rewetting' and 'partial rewetting'. Long-term commitment from all peatland restoration stakeholders is crucial, especially when it comes to long-term financial commitment.

Restoration requires social support so that restoration projects - with their important benefits to the ecosystem and society - can be delivered. Social engagement, in the form of education and information dissemination, is equally important to explain the mutual benefits between ecosystem and society; such engagement needs to include both formal and informal approaches to include stakeholders from different levels and backgrounds.

It is also possible that improving an indicator for a particular criterion could be to the detriment of another indicator for different criteria. One example of this is that the harvest of products from species with high economic value could improve household income, while it could also reduce the capacity of carbon sinks.

During expert consultation, the importance of establishing transition criteria also emerged as crucial for the ongoing sustainability of an area, particularly after 'external' interventions for peatland restoration end. For instance, after a programme ends in a particular place, establishing criteria like 'the village will adopt or integrate the existing programme into village regulation' ensures a level of continuity for the completed programme. It is also important to consider funding sustainability as part of transition criteria, to ensure the continuation of programmes. This continued funding support could either come through the market system, or through creating new markets for alternative livelihoods, continuous funding support from stakeholders, or local actors taking financial responsibility for restoration activities.

Moving forward, the various sets of principles, criteria and indicators will be finalized through further consultation and information exchange, before appropriate verifiers are identified for each of these sets of criteria and indicators. Subsequently, principles, criteria and indicators will then be tested on the ground, with support from relevant practitioners and government entities entrusted with peatland restoration. After testing their relevance, the finalized principles, criteria and indicators will be adopted and implemented more widely. The involvement of Regional Peatland Restoration Team (Tim Restorasi Gambut Daerah, TRGD) will be considered, especially their work connected to the Peat Care Village (Desa Peduli Gambut, DPG) programme. 


\section{References}

Bonn, A., T. Allott, M. Evans, H. Joosten, and R. Stoneman. 2016. Peatland restoration and ecosystem services: science, policy and practice. Cambridge University Press.

Dargie, G. C., S. L. Lewis, I. T. Lawson, E. T. Mitchard, S. E. Page, Y. E. Bocko, and S. A. Ifo. 2017. Age, extent and carbon storage of the central Congo Basin peatland complex. Nature 542:86-90.

FAO. 2020. Peatland mapping and monitoring - Recommendations and technical overview., FAO, Rome.

Herrick, J. E., G. E. Schuman, and A. Rango. 2006. Monitoring ecological processes for restoration projects. Journal for Nature Conservation 14:161-171.

Jaenicke, J., J. Rieley, C. Mott, P. Kimman, and F. Siegert. 2008. Determination of the amount of carbon stored in Indonesian peatlands. Geoderma 147:151-158.

Page, S. E., J. O. Rieley, and C. J. Banks. 2011. Global and regional importance of the tropical peatland carbon pool. Global Change Biology 17:798-818.

Pokorny, B., and M. Adams. 2003. What do criteria and indicators assess? An analysis of five C\&I sets relevant for forest management in the Brazilian Amazon. The International Forestry Review 5:20-28.

Prabhu, R., C. J. P. Colfer, and R. G. Dudley. 1999. Guidelines for developing, testing and selecting criteria and indicators for sustainable forest management: a C\&I developer's reference. Cifor.

Warren, M., K. Hergoualc'h, J. B. Kauffman, D. Murdiyarso, and R. Kolka. 2017. An appraisal of Indonesia's immense peat carbon stock using national peatland maps: uncertainties and potential losses from conversion. Carbon Balance Manag 12:12.

Yu, Z., J. Loisel, D. P. Brosseau, D. W. Beilman, and S. J. Hunt. 2010. Global peatland dynamics since the Last Glacial Maximum. Geophysical Research Letters 37. 


CIFOR Working Papers contain preliminary or advance research results on tropical forest issues that need to be published in a timely manner to inform and promote discussion. This content has been internally reviewed but has not undergone external peer review.

Peatland restoration is a complex process that requires continuous monitoring to enable an adaptive, iterative landscape approach that meets local conditions, needs and aspirations. Peatland restoration monitoring can inform design, strategy, site selection and management approaches, as well as improve restoration outcomes through adjustments. Tested protocols that assess the fate of restored ecosystems are useful so practitioners and institutions can determine the success and failures of peatland restoration objectively. Of particular help are simple indicators that are easy to recognize, measure and monitor over time. A scientifically robust, reliable, and practical set of criteria and indicators could help key stakeholders assess the progress and outcomes of restoration efforts, so they can evaluate advances and whether restoration is heading in the right direction.

With this in mind, CIFOR organized a series of online workshops between September and December 2020, to explore and identify criteria and indicators for tropical peatland restoration through a consultative process involving practitioners, government agencies, researchers and community members. From this process it emerged that effective criteria and indicators for peatland restoration should capture aspects relating to rewetting drained peatlands, reducing fire risks, revegetating landscapes, reinforcing local governance structures, and revitalizing local communities' socio-economic conditions (five Rs). The identified criteria and indicators cover four aspects of peatland restoration - biophysical, social, economic and governance - to capture the range of topics and issues that impact peatlands. These criteria and indicators are now ready for field testing, and when these have been successfully validated, can be adapted and adopted by relevant agencies for future restoration monitoring.

\section{cifor.org | forestsnews.cifor.org}

\section{USAID}

